\title{
ESTRUTURAS POTENCIAIS DE GÊNEROS NA ANÁLISE TEXTUAL E NO ENSINO DE LÍNGUAS
}

\author{
Orlando Vian Jr.
}

\begin{abstract}
Resumo: A partir (i) do conceito de Gênero de Hasan (1989), com sua composição em estágios obrigatórios, opcionais e recursivos, (ii) do conceito de Registro de Halliday (1989), com suas variáveis de campo, relações e modo, e (iii) da inter-relação gênero/registro em níveis contextuais de cultura e de situação, são aqui analisados textos de vídeos institucionais com o objetivo de evidenciar que o estudo da configuração contextual (HASAN, 1989) e dos estágios que compõem os textos fornece pistas para a compreensão de aspectos da organização textual e dos gêneros aos quais os textos pertencem. Argumenta-se, ainda, que os elementos da configuração contextual podem ser utilizados no ensino-aprendizagem de línguas estrangeiras e de língua materna a partir da adoção de gêneros do discurso como objeto de ensinoaprendizagem.
\end{abstract}

Palavras-chave: gênero discursivo; texto; gramática sistêmico-funcional; ensino de línguas.

[...] o semear é uma arte que tem mais de natureza que de arte. Nas outras artes tudo é arte; na Música tudo se faz por compasso, na Arquitetura tudo se faz por regra, na Aritmética tudo se faz por conta, na Geometria tudo se faz por medida. O semear não é assim. É uma arte sem arte; caia onde cair.

(Pe. Antônio Vieira, Sermão da Sexagésima, V)

\footnotetext{
* Professor da Universidade Federal do Rio Grande do Norte, Natal, RN, Brasil. Doutor em Linguística Aplicada. Email: <orlando@cchla.ufrn.br>.
} 


\section{INTRODUÇÃO}

Este texto parte de trabalho anterior (VIAN JR, 1997) e objetiva discutir como os textos estruturam-se em estágios a partir da perspectiva sistêmico-funcional de linguagem (HALLIDAY, 1989; HALLIDAY; HASAN, 1989), bem como a importância de tais estruturas para os estudos sobre texto e gênero e para métodos de ensino de línguas materna e estrangeiras.

Como forma de ilustrar a análise textual, são utilizados quatro textos de vídeos institucionais de empresas multinacionais que atuam no Brasil como corpus para análise textual, e, para a apresentação das estruturas dos textos em estágio, num primeiro momento, são apresentadas as variáveis de registro propostas por Halliday (1989); com base nesses elementos, discuto como os textos estruturam-se em estágios a partir dos conceitos de Hasan (1989), Martin (1992), Eggins (1994), Eggins e Martin (1997) e Martin e Rose (2003, 2008). Apresento, em seguida, os estágios que compõem os textos, bem como as características principais de cada um e sua classificação em obrigatórios, opcionais e recursivos.

A conjugação desses elementos possibilita, finalmente, a determinação da Estrutura Potencial do Gênero (EPG, a partir daqui) à qual os textos pertencem para que se encaminhe a discussão sobre como tais estruturas podem ser utilizadas no ensino de línguas.

\section{O CONTEXTO DE CULTURA: GÊNERO}

Os textos aqui utilizados para análise foram extraídos de vídeos institucionais, um dos meios de divulgação da propaganda institucional, que se insere no contexto mais amplo da propaganda, preocupando-se, entre outras funções, em criar, alterar ou reforçar imagens sobre as empresas.

O termo institucional é empregado, por vezes, como corporativo, o que, segundo Gracioso (1995), deve-se ao fato da popularização do termo no Brasil, ao passo que em outros países é empregado como 
propaganda corporativa, pois a palavra 'corporativa' expressa de maneira mais precisa o sentido da propaganda institucional, que tem por função "influir sobre o comportamento das pessoas, através da criação, mudança ou reforço de imagens e atitudes mentais" (GRACIOSO, 1995, p. 23).

O objetivo da propaganda institucional, portanto, é legitimar a empresa, criando uma receptividade duradoura junto ao público, sendo um dos diversos veículos utilizados pelas empresas para divulgar sua imagem. Os vídeos institucionais podem ainda ser classificados como um dos meios de divulgação visual/auditiva e, de acordo com a classificação de Torquato (1986), podem também ser considerados como um meio de comunicação descendente centrífuga, ou seja, aquela que se refere ao processo de transmissão de informações da cúpula para a base.

Os textos de vídeos institucionais que compõem o corpus aqui analisado são de empresas multinacionais originárias de diferentes países. Por questões de preservação de identidade, as empresas receberam um nome fictício, que se inicia pela abreviação da palavra companhia (cia), seguido de um número cardinal por extenso; assim, temos: Ciaum para a empresa que produz alumínio e tem sua matriz nos Estados Unidos; a empresa produtora de equipamentos para produção de energia elétrica, Ciadois, é originária da Suécia; a Ciatrês, empresa produtora de freios, é da Alemanha e a Ciaquatro, empresa prestadora de serviços de auditoria e de consultoria, é da Inglaterra.

Como membros de uma sociedade e como produtores em potencial de textos, os usuários da língua trocam significados com seus interlocutores. Para que estes significados sejam trocados, torna-se necessário o conhecimento da estruturação do gênero a ser utilizado: uma conversa telefônica, a compra de um produto, a discussão de um determinado assunto ou qualquer outro dos inúmeros gêneros à disposição do usuário em seu cotidiano.

Cada um desses tipos de evento objetiva determinado significado social, sendo possível definir os elementos que o estruturam e como estes se organizaram para a formação do todo. Chamaremos a cada uma dessas partes de estágios, com base no proposto por Hasan (1989) e Martin (1992). 
Os estágios de um texto podem apresentar três características básicas. Existem aqueles que sempre irão ocorrer naquele evento comunicativo específico. Estes estágios, dessa forma, são denominados obrigatórios, uma vez que ocorrem em todos os exemplares e são determinantes para a caracterização do gênero a que os textos pertencem.

Há, por outro lado, elementos que podem aparecer ou não. A estes estágios, que podem ser retirados do texto e que não afetam a sua estrutura, chamaremos de estágios opcionais.

Existem, ainda, elementos que podem ser repetidos, ou ocorrer em lugares diferentes do texto. Os estágios que podem ocorrer mais de uma vez no mesmo texto denominam-se estágios recursivos.

Com base nesses pressupostos, os estágios obrigatórios, opcionais e recursivos de cada um dos textos que formam o corpus serão caracterizados no item 4 , do ponto de vista de seu conteúdo.

\section{O CONTEXTO DE SITUAÇÃO: REGISTRO}

Como minha premissa é a análise do gênero a partir de uma perspectiva sistêmico-funcional, informações sobre os participantes do evento, bem como sobre o papel que a linguagem exerce, são de extrema importância. Analisarei, assim, a comunidade discursiva com base nas variáveis de registro propostas por Halliday (1989), que visam a interpretar o contexto social no qual os textos, bem como seus significados, são trocados.

As variáveis sugeridas por Halliday (1989) estabelecem as características do contexto da situação, especificando o campo do evento, ou seja, o que está acontecendo; quem participa do contexto, o papel que desempenham e o status que têm no contexto, pressupondo características das relações, o papel que desempenham e o status que têm no contexto e o modo, que se refere ao papel que a linguagem exerce, ou seja, o que se pretende atingir com o texto em termos persuasivos ou didáticos, por exemplo. Estabelecem-se, assim, as seguintes 
características situacionais dos vídeos institucionais produzidos por empresas multinacionais sediadas no Brasil:

- Campo: Discurso institucional para motivação do funcionário/cliente.

- Relações: Falantes: narradores anônimos falando pelas empresas. Ouvintes: novos funcionários e/ou clientes em potencial.

- Modo: Linguagem falada, a partir de texto escrito, associada a imagens em vídeo.

A configuração contextual (CC) é o conjunto específico de valores que realizam o campo, as relações e o modo do discurso (HASAN, 1989, p. 55), e, a partir da definição dos elementos da CC de cada texto, podemos fazer considerações sobre as estruturas textuais propriamente ditas (HASAN, 1989, p. 56). É a partir da CC que poderemos fazer predições sobre que elementos da estrutura textual são obrigatórios, bem como quais são opcionais ou recursivos, além de considerações sobre como estes estágios estruturam-se no texto de forma a transmitir os significados que transmitem.

\section{OS TEXTOS E SUA ORGANIZAÇÃO EM ESTÁGIOS}

Para compreender como os significados são transmitidos pelos textos, é necessário analisar os elementos que compõem a sua configuração contextual. Dessa forma, são apresentados a seguir os estágios que compõem os textos analisados.

\subsection{Os estágios obrigatórios}

Os estágios obrigatórios caracterizam os gêneros discursivos pelo fato de estarem presentes em todos os textos que pertençam àquele gênero (HASAN, 1989). Figurativamente, estes estágios funcionam como uma 'moldura' para o texto: eles têm como função fornecer uma estrutura, a partir da qual as demais funções se inserem. 
Toda carta de negociação, por exemplo, pressupõe o estabelecimento da rede da relação das negociações no início e, no final, a finalização (SANTOS, 1996). A partir desses elementos os demais são inseridos, de acordo com as variáveis do evento comunicativo em questão.

No corpus analisado, as funções obrigatórias, apesar de aparecerem em todos os textos, não seguem uma estrutura fixa. Os estágios ocorrem, mas podem estar em lugares diferentes do texto. $\mathrm{O}$ estágio Fundação da empresa, por exemplo, é obrigatório em todos os textos, ocorrendo, para três das empresas, em posição inicial. Para a Ciadois, entretanto, este estágio aparece em direção ao final do texto. O conceito de estágio obrigatório deve ser entendido aqui como um estágio que é comum a todos os textos do corpus, mas que não ocorre em ordem idêntica em todos.

O estágio Estrutura organizacional aparece dividido em dois subestágios. Como estamos tratando de empresas multinacionais, os subestágios objetivam a apresentação tanto da atuação em outros países do mundo - principalmente no país onde estão instaladas suas matrizes - quanto no Brasil.

Esses estágios, como já dissemos, estruturam o texto como um todo, os demais (opcionais e recursivos) vêm apenas fornecer maiores informações sobre a empresa, mas, se retirados, não afetam o objetivo geral do texto. Os estágios do texto foram delimitados de acordo com o seu conteúdo, que estão, por sua vez, associados às imagens apresentadas no vídeo. Como o objetivo é apresentar a análise da estrutura textual, os elementos visuais, embora funcionem como suporte para a linguagem verbal, não serão tratados aqui.

Existem, para todas as empresas, seis estágios obrigatórios:

Introdução

Fundação da empresa

Estrutura organizacional

Exaltação do funcionário

Pré-conclusão

VIAN JR. - Estruturas potenciais de gêneros... 


\section{Conclusão.}

As funções e os objetivos, bem como recortes ilustrando cada estágio, serão apresentados a seguir.

O primeiro estágio obrigatório, Introdução, funciona como fator de inserção do espectador no contexto e apresenta duas características básicas: (i) ou as introduções iniciam dando informações históricas sobre a empresa ou o produto que esta fabrica ou (ii) iniciam fazendo generalizações, conforme ilustram os seguintes exemplos:

Durante a Revolução Industrial, Samuel Lowell Cia estabeleceuse em Londres, em 1850, como contador independente. Alguns anos depois, em 1856, admitiu como sócio Edwin Quatro, dando origem ao nome Ciaquatro. (Ciaquatro)

[...] Hoje é o começo de uma nova etapa profissional em sua vida, pois você se torna um profissional Ciatrês. E para situá-lo na realidade de nossa empresa, vamos fazer uma viagem ao início da Ciatrês. (Ciatrês)

Se levarmos em consideração o propósito pragmático dos textos em análise, percebe-se a importância desse estágio, uma vez que a empresa está interessada no ato de apresentar-se, e, por outro lado, o ouvinte tem como expectativa conhecer os produtos fabricados pela empresa, ou os serviços por ela prestados, além de sua história e filosofia.

Apesar de o estágio Fundação da empresa ser comum a todos os textos, para a Ciadois o estágio não ocorre no início do texto, como é o caso das demais, ocorrendo no final. No item 5, onde são apresentadas as Estruturas Potenciais do Gênero (EPGs) dos textos, este estágio vem anteposto de um asterisco, indicando que é um estágio obrigatório, mas não segue a ordem fixa dos demais (cf. Figura 1). Este estágio tem por objetivo apresentar informações sobre o país de origem da empresa, funcionando como elemento fornecedor de credibilidade, transmitindo ao cliente/funcionário a visão de que se trata de uma empresa com grande capacidade de atuação, tendo sido fundada num país de primeiro mundo, e que pode colaborar ainda mais com o desenvolvimento do país onde está instalada. 
Esquematicamente, este estágio vem logo após a introdução, funcionado como elemento que confirma a grande capacidade da empresa.

O estágio Estrutura organizacional é, segundo informantes especializados em produção de vídeos institucionais, um fator de grande importância, principalmente para o funcionário, pois a empresa tem como objetivo uma integração deste à empresa. A partir do vídeo, o funcionário tem uma visão de como a empresa funciona, para, então, saber qual o papel que vai exercer dentro desse conjunto.

Nos textos dos vídeos estudados, todas as empresas expõem sua estrutura da mesma forma: informam ao cliente/funcionário primeiramente seu (a) status internacional, para que se tenha a dimensão exata de sua grandiosidade, para depois informar (b) o status nacional, consequentemente indicando de que forma ela pode colaborar com o país e, mais ainda, com o cliente e/ou funcionário.

Quando expõem seu status internacional, as empresas enfatizam geralmente o número de filiais que possuem pelo mundo ou o número de países nos quais atuam, ou por vezes, apenas sinalizam sua grandeza. Vejamos alguns exemplos:

[...] opera em mais de dezessete países. (Ciaum)

Maior grupo mundial de engenharia da energia. (Ciadois)

[...] possui várias unidades em diferentes países como a Alemanha, Estados Unidos, Bélgica [...] (Ciatrês)

[...] está presente em todo o mundo [...] (Ciaquatro)

Como se vê, os diferentes países onde atuam, bem como o número de unidades espalhadas pelo mundo, fornecem subsídios para que o cliente ou funcionário tenha a visão exata da amplitude da empresa.

Neste estágio, assim como no estágio subsequente - que trata da atuação nacional -, as empresas procuram enfatizar informações como o porte da instituição, seu pioneirismo, o tempo de atuação no mercado, entre outros, que são fatores que dão credibilidade à empresa. As empresas apresentam também informações sobre as diversas áreas de 
atuação e em que partes do país e do mundo atuam, mostrando a sua grandiosidade.

Para descrição de sua atuação no país, através do estágio Status nacional, as empresas parecem recorrer mais comumente aos benefícios sociais que podem trazer para o país, ou, ainda, às grandes obras que desenvolveram no país:

$[\ldots]$ contribuindo para a auto-suficiência do mercado interno [...] (Ciaum)

No país o grupo é formado por várias empresas [...] (Ciadois)

[...] mantém escritórios nas mais importantes cidades do Brasil..." (Ciaquatro)

Através de informações como essas, tanto o cliente quanto o funcionário podem ter uma visão de como a empresa colabora para o desenvolvimento do país. Fica implícita também a necessidade de a empresa fornecer ao cliente e/ou funcionário dados autobiográficos, o que parece contribuir para acentuar seu sucesso e sua capacidade.

As empresas, após a exposição de sua estrutura organizacional e de outros elementos ligados a sua história e objetivos, passam a exaltar o funcionário e sua importância para a empresa através do estágio Exaltação do funcionário. Conforme sinalizado por Pinho (1990), faz parte da propaganda institucional apresentar fatos e informações sobre o pessoal da empresa. Neste evento comunicativo, especificamente, o funcionário está em fase de admissão na empresa e assistir ao vídeo faz parte de sua integração à equipe; por essa razão, torna-se necessária a visão do todo, para que então possa visualizar o seu papel neste contexto. A Ciaum, por exemplo, sinaliza a sua preocupação voltada para o humano e para o social:

[...] a empresa vem procurando transmitir a idéia de que a sua liderança no mercado seja reconhecida, não só pela excelência de seus produtos e serviços, mas também pela qualidade superior de seus quase sete mil funcionários.

Existe a preocupação em reconhecer o funcionário, contudo, não se atribui a ele características humanas; eles são reconhecidos por sua 'qualidade superior', dando a impressão da comparação a um produto. 
Os funcionários desempenharão, assim, vários papéis de suma importância, eles serão:

[...] a principal matéria-prima da empresa. (Ciaum)

[...] seu [da empresa] maior patrimônio. (Ciadois)

[...] o principal responsável pela qualidade de nossos produtos. (Ciatrês)

Este estágio parece ser necessário nesse evento comunicativo por ser o primeiro contato oficial entre empresa e funcionário, que precisa ter a noção exata de sua função no todo empresarial. No caso do cliente, por outro lado, transmite-se a preocupação da empresa com o ser humano. A Ciatrês é a única a explicitar o seu 'interesse' no funcionário para o bem de si própria, advertindo:

É importante que no dia-a-dia colaboremos com a empresa e com os nossos colegas de trabalho, para constante melhoria dos processos, produtos e ambiente de trabalho pois assim todos temos a ganhar.

É no estágio Pré-conclusão que a empresa vai apresentar os seus sentimentos em relação à sociedade onde atua e mostrar que é uma entidade empresarial engajada no desenvolvimento da sociedade. Para isso, a empresa utiliza-se de um léxico referente a sentimentos humanos, aparentando mostrar uma preocupação não só com o funcionário, mas com a sociedade como um todo e seu papel para torná-la mais humana.

Nesse estágio, todas as empresas realizam algo semelhante a um resumo de suas realizações e intenções no país, relacionando seus principais objetivos e mostrando-se preocupadas com o destino dos funcionários e da sociedade:

Tradição. Visão de futuro. Investimentos contínuos em pesquisa e desenvolvimento. Descentralização administrativa. Valorização do homem. Respeito ao meio-ambiente. E muito trabalho. É assim que a Ciadois conquistou a liderança mundial na engenharia da energia e se tornou parte integrante das comunidades em que participa. (Ciadois)

A Ciatrês, por outro lado, demonstra preocupação consigo mesma, assumindo que:

VIAN JR. - Estruturas potenciais de gêneros... 
A empresa ganha, pois garante a sua rentabilidade e imagem junto ao público consumidor, o que vai lhe garantir a continuidade de suas operações aqui no Brasil.

As outras três empresas dão a impressão de deixarem de existir, passando a preocupar-se com os problemas sociais, listando todos os benefícios que podem gerar para o funcionário e para o país, empregando, por vezes, verbos típicos de ações humanas, como é o caso da Ciaum que "trata com maior carinho o meio-ambiente". A Ciadois lista os seus objetivos, os quais a transformaram em "parte integrante das comunidades em que participa". A Ciaquatro, por sua vez, "tem orgulho de sua liderança”. Esse estágio, como se vê, prepara o funcionário ou o cliente para o fechamento do texto, colocando-o a par de todas as características da empresa da qual ele vai fazer parte ou utilizar os produtos/serviços.

Para todas as empresas, o estágio Conclusão é o fechamento do texto e, portanto, o fechamento do evento comunicativo; logo, o final da primeira relação estabelecida entre a empresa e seu funcionário e/ou cliente em potencial. Deve garantir, portanto, que a relação entre ambos continue saudável. Para isso, todas as empresas do corpus utilizam-se do mesmo recurso retórico: uma frase-feita, praticamente beirando o lugarcomum, para expressar toda a sua autoridade e capacidade, de forma a transmitir toda a credibilidade aos ouvintes. A Ciatrês é a única a incluir o funcionário nesse mote, adotando, para isso, em vez de 'funcionário', a palavra colaborador:

Qualidade é a imagem da Ciatrês. Qualidade é acima de tudo a imagem de cada um de nós colaboradores. Sejam bem-vindos à Ciatrês.

As demais utilizam-se de frases curtas, motes, praticamente, que resumem a que a empresa veio:

Esta é Ciaum, símbolo de qualidade industrial, de desenvolvimento econômico e de paz social, uma empresa que adota como lema 'A excelência como missão'. (Ciaum)

Ciadois, uma empresa multidoméstica. (Ciadois)

A Ciaquatro está sempre em busca de novas formas de cooperar com a sociedade. (Ciaquatro) 


\subsection{Os estágios opcionais}

Os estágios opcionais dos vídeos institucionais que compõem o corpus analisado ocorrem em função do ramo de negócios da empresa. A sua ocorrência ou não depende de fatores ligados ao campo do evento em questão, uma vez que cada empresa lança mão de estágios diferentes para fazer explanações específicas sobre a natureza de seu produto ou serviço ou sobre algo específico sobre seu funcionamento, que, entretanto, aparecendo isoladamente, não descaracterizariam o texto como parte do gênero a que pertence.

No caso da Ciaum, cada um dos estágios opcionais refere-se a mudanças específicas relacionadas exclusivamente a esta empresa. O estágio Usos do produto refere-se às várias utilidades do alumínio, o produto fabricado pela empresa. O estágio Mudanças organizacionais referese à mudança na administração e à entrada de novo acionista. Os três estágios restantes (Recursos humanos, Preocupação com o meio-ambiente e Obras sociais) referem-se à filosofia de trabalho da empresa e à sua preocupação com a sociedade. Daí a necessidade de estágios opcionais que realizassem a função de expor esses diferenciais. Esses estágios, por serem opcionais, podem aparecer em qualquer ordem no texto, ou simplesmente não aparecer, não comprometendo a caracterização do texto como parte de determinado gênero.

O vídeo da Ciadois, por outro lado, não apresenta estágios opcionais, apenas estágios obrigatórios e recursivos. Ou seja, mesmo apresentando seus produtos, a empresa não se utiliza de nenhum estágio opcional para fazê-lo. Tal fato acentua a característica de os textos não possuírem uma ordem fixa. De acordo com contatos informais com pessoas ligadas à produção de vídeos institucionais, caso a empresa lance um produto novo, ou efetue mudanças organizacionais, poderá incluir tais informações nos vídeos existentes ou produzir um novo vídeo para esse fim. A ordem seguida para a inclusão desses elementos, contudo, é definida através de critérios determinados pela empresa, ocorrendo, por vezes, de maneira aleatória, ou ligada a algum outro elemento existente no vídeo relacionado à nova informação a ser incluída, o que reforça a nossa hipótese da ausência de ordem nesse tipo de texto.

São dois os estágios opcionais apresentados pela Ciatrês (Departamentos de produção e Departamentos administrativos); o primeiro

VIAN JR. - Estruturas potenciais de gêneros... 
descreve todo o processo de produção dos freios, enquanto o estágio seguinte explicita os departamentos que dão apoio para melhores condições de trabalho.

Finalmente a Ciaquatro, por ser uma empresa de serviços, precisa deixar bem evidente a eficácia dos serviços prestados, e, para tanto, utiliza-se de dois estágios opcionais para falar da Filosofia da empresa, ou seja, de como dispõe de recursos para realizar os serviços com eficiência, para depois, num outro estágio opcional, descrever o Compromisso com o nome da empresa e sua solidez no mercado, que são marcas registradas que garantem a qualidade dos serviços.

Os estágios opcionais referem-se a cada uma das características da empresa que a diferencia das demais: são aqueles que definem o ramo de negócios da empresa, apresentando suas características únicas. Se retirados do texto, entretanto, esses estágios não comprometem a compreensão nem descaracterizam o gênero; prova disso é que o texto da Ciadois não possui estágios opcionais.

\subsection{Os estágios recursivos}

Em cada um dos textos observa-se um padrão retórico que funciona como forma de reforçar a capacidade da empresa junto ao cliente ou funcionário. Esses padrões são representados através dos estágios recursivos a seguir, que se desenvolvem na descrição da estrutura organizacional da empresa.

A Ciaum adota um padrão que objetiva mostrar a vasta atuação da empresa em várias cidades do país. Assim, ao descrever sua estrutura organizacional, a empresa inicia explicitando o local onde se localiza, grifados nos exemplos, e, em seguida, os fatores que a levaram a se instalar naquele local:

Poços de Caldas, Minas Gerais, esta cidade com cerca de 110 mil habitantes fica [...]

Estamos agora em São Luís do Maranhão. (...) Este local foi escolhido em função de [...]

Em Itapeçuma, próxima a Recife no Estado de Pernambuco, a Ciaum tem $[\ldots .$. 
Esta é a fábrica da Ciaum Alumínio em Pidamonhangaba, no Estado de São Paulo. Aqui [...]

Uma das mais novas unidades industriais da Ciaum é a fábrica de Sorocaba, que fica [...]

Esses estágios ocorrem cinco vezes no texto da Ciaum, culminando com um outro estágio onde há uma comparação entre o que a empresa faz no Brasil e sua atuação no mundo, convergindo num só objetivo: "oferecer a última palavra em qualidade e tecnologia".

O padrão adotado pela Ciadois objetiva mostrar a sua capacidade de atuação nacional, partindo, contudo, do Status internacional, desenvolvendo, a partir daí, o seu Status nacional em cada uma das áreas onde atua. Essa empresa apoia-se, porém, na quantidade e na magnitude dos clientes. Após apresentar suas formas de atuação no país, ratifica tal capacidade com os clientes que possui e que utilizaram os produtos e serviços da empresa naquela área específica.

Ao final dessa cadeia de padrões, funcionando como o fechamento da cadeia retórica, a empresa transfere o seu sucesso em todas as áreas aos seus funcionários, que passam a ser a principal razão da capacidade da empresa:

Com tantos recursos do mais alto nível, a Ciadois sabe que seu maior patrimônio são seus funcionários, onde se concentram os maiores investimentos e toda a capacitação acumulada pelo grupo. Investindo no homem e acreditando no futuro do Brasil.

A estrutura organizacional da Ciatrês é apresentada através do padrão denominado Oferecimento de serviços, no qual a empresa descreve sua estrutura como um bem sendo oferecido ao funcionário. Em contraposição aos bens oferecidos, esta solicita a colaboração do funcionário para que os padrões da empresa sejam mantidos, da seguinte maneira:

Há também os serviços voltados aos nossos colaboradores.

Mas a sua segurança depende principalmente de você.

E o Setor de Folha de Pagamento de nossos funcionários. [estágio 6.1] 
Todavia, cabe a você colaborador a correta marcação de seu ponto. [estágio 7.1]

Para descrição de sua estrutura organizacional, a Ciaquatro, a única empresa de serviços do corpus, adota um padrão retórico de problema-solução. Como não existe a possibilidade de mostrar visualmente os serviços que realiza, a empresa transmite credibilidade através dos serviços que presta e da quantidade de clientes que possui.

Dessa forma, esse padrão funciona da seguinte maneira: para descrever sua estrutura organizacional, a empresa antecipa um problema de determinada área e, logo a seguir, explicita como os profissionais da empresa desempenham sua função de maneira a resolvê-lo. Nos dois grupos de exemplos a seguir, o primeiro exemplo do grupo [A] apresenta o problema e o estágio seguinte [B] as soluções:

No universo dos negócios, cada lance exige concentração e movimentos certos. [A]

A Ciaquatro acompanha empresas que trabalham sob pressão extrema e tem ajudado centenas delas a tomar decisões certas nos momentos difíceis [...] [B]

Numa empresa dinâmica, voltada para o seu próprio desenvolvimento, a necessidade de tomar decisões estratégicas pode surgir de uma hora para outra. [A]

Esses momentos decisivos não ocorrem todos os dias. Quando surgem, porém, exigem deliberações baseadas em dados e informações confiáveis e numa compreensão profunda da empresa e do mercado em que ela atua. [B]

Em todos os textos dos vídeos institucionais aqui analisados, as empresas utilizam-se de estágios recursivos para descrever sua estrutura organizacional, adotando um padrão retórico de maneira a acentuar a sua capacidade e, assim, legitimar-se. Destacamos, entretanto, o padrão retórico utilizado pela empresa de serviços, que se utiliza de recursos metafóricos para legitimar os seus serviços. Como não será discutida neste texto a questão visual nem multimodal, apenas os elementos da estrutura textual, esses recursos não serão apresentados (cf. VIAN JR, 1997, para explicitação desses elementos). 


\section{AS ESTRUTURAS POTENCIAIS DO GÊNERO}

A partir da caracterização de cada estágio componente dos textos, bem como das considerações do ponto de vista institucional, procedemos à esquematização da Estrutura Potencial do Gênero (EPG) de cada um dos textos com base nos símbolos propostos por Hasan (1989) e Eggins (1994):

$\wedge$ sequência

* = estágio é obrigatório, porém não ocorre sempre na mesma ordem.

( ) = estágios são opcionais

$\downarrow=$ estágios recursivos

$\sqcup\{\}=$ recursivos e na ordem fixa estabelecida entre chaves.

Optamos por utilizar as iniciais de cada estágio para proporcionar uma visualização do texto como um todo; elas aparecem desenvolvidas após a figura.

Os textos, dessa forma, apresentam-se assim estruturados:

\begin{tabular}{|c|c|}
\hline Ciaum: & $\begin{array}{l}\left.\mathrm{I}^{\wedge *} \mathrm{FE}^{\wedge}(\mathrm{UP})^{\wedge} \mathrm{EO} \downarrow\{\lrcorner \mathrm{SI} \mathrm{I}^{\wedge} S N^{\wedge} S N^{\wedge} S N^{\wedge} S N^{\wedge} S N\right\}^{\wedge}, S I^{\wedge} \\
(\mathrm{MO})^{\wedge}(\mathrm{RH})^{\wedge} * \mathrm{EF}^{\wedge}(\mathrm{PMA})^{\wedge}(\mathrm{OS})^{\wedge} \mathrm{PC}^{\wedge} \mathrm{C}\end{array}$ \\
\hline Ciadois: & $\mathrm{I}^{\wedge} \mathrm{EO} \downarrow\left\{\mathrm{SI}^{\wedge} S N^{\wedge} C l^{\wedge} S N^{\wedge} C l^{\wedge} S N^{\wedge} C l^{\wedge} S N^{\wedge} C\right\}^{\wedge} * \mathrm{EF}^{\wedge} * \mathrm{FE} \downarrow^{\wedge} S N^{\wedge} \mathrm{PC}^{\wedge} \mathrm{C}$ \\
\hline Ciatrês: & $\begin{array}{l}\mathrm{I}^{\wedge} * \mathrm{FE}^{\wedge} S I^{\wedge} \mathrm{Cl}^{\wedge} * \mathrm{EF}^{\wedge} \mathrm{EO} \perp\left\{(\mathrm{DP})^{\wedge}(\mathrm{DA})^{\wedge} O S^{\wedge} S C^{\wedge} O S^{\wedge} S C^{\wedge}\right. \\
\left.O S^{\wedge} S C^{\wedge} O S^{\wedge} S C^{\wedge} O S^{\wedge} S C\right\}^{\wedge} \mathrm{PC} C^{\wedge} \mathrm{C}\end{array}$ \\
\hline Ciaquatro: & $\begin{array}{lllll}\left.\mathrm{I}^{\wedge} \mathrm{FE}^{\wedge} \mathrm{SI} \mathrm{I}^{\wedge}(\mathrm{FilE})^{\wedge} \mathrm{SN} \mathrm{N}^{\wedge}(\mathrm{CN})^{\wedge} \mathrm{Cl}^{\wedge} \mathrm{EO}\right\lrcorner\left\{S^{\wedge} P^{\wedge}\right. & S^{\wedge} P^{\wedge} & S^{\wedge} P^{\wedge} & S^{\wedge} P^{\wedge} \\
\left.\left.S^{\wedge} P\right\}^{\wedge} * \mathrm{EF}\right\lrcorner\left\{P^{\wedge} S\right\}^{\wedge} \mathrm{PC}^{\wedge} \mathrm{C} & & & \end{array}$ \\
\hline
\end{tabular}

Figura 1 - Estrutura potencial dos textos.

Também para visualização da estrutura textual e para a percepção da organização do texto em estágios, são utilizadas letras maiúsculas em negrito para os estágios obrigatórios, letras maiúsculas em fonte normal para os estágios opcionais e letras maiúsculas em itálico para os estágios recursivos.

VIAN JR. - Estruturas potenciais de gêneros... 
As iniciais de cada estágio são utilizadas como forma de mostrar cada um deles e sua posição na organização textual, de acordo com a seguinte nomenclatura:

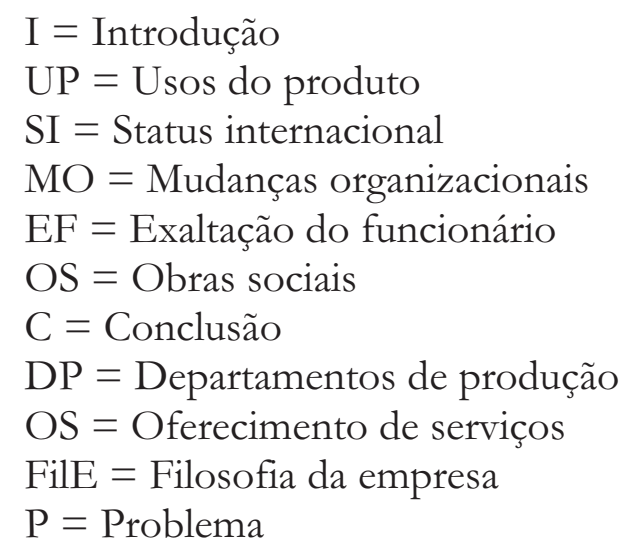

\author{
$\mathrm{FE}=$ Fundação da empresa \\ $\mathrm{EO}=$ Estrutura organizacional \\ $\mathrm{SN}=$ Status nacional \\ RH $=$ Recursos humanos \\ PMA = Preocupação com o meio ambiente \\ $\mathrm{PC}=$ Pré-conclusão \\ $\mathrm{Cl}=$ Clientes \\ $\mathrm{DA}=$ Departamentos administrativos \\ SC = Solicitação de colaboração \\ $\mathrm{CN}=$ Compromisso com o nome \\ $\mathrm{S}=$ Solução
}

Estas estruturas, como se pode observar na Figura 1, possibilitam vislumbrar os textos como um todo e como os estágios se distribuem, fornecendo-nos informações úteis sobre estruturas textuais. No entanto, não devem ser encaradas como algo prescritivo, pois só as variáveis de contexto é que vão definir a estrutura. Nossa proposta é a de que só se chega a estruturas desse tipo após considerações sobre o contexto no qual o texto é produzido e utilizado, seus participantes, seu campo e todos os demais elementos envolvidos, como apresentados nos itens anteriores em relação às variáveis do contexto de cultura e de situação.

Socialmente, o que ocorre é que não há uma recriação do gênero a ser utilizado pelo usuário. Uma vez trocado entre os interlocutores num meio socialmente organizado, este pode ser estruturado e esquematizado, e, nas próximas vezes em que forem necessários para a interação humana, os modelos serão utilizados ou produzidos sem a necessidade de recriação, o que tornaria a comunicação um tanto quanto complexa. O que nos remete também à definição de gênero proposta por Bakhtin (1992), e origem de praticamente todas as definições de gêneros utilizadas atualmente nos estudos linguísticos: "tipos relativamente estáveis de enunciados".

É claro que outras variantes influenciarão no texto em função do campo, das relações e do modo do discurso; sua estrutura básica, contudo, será a mesma no momento de uma troca social específica e terá como função um dado evento comunicativo. 


\section{O USO DAS EPGS NO ENSINO}

As estruturas dos textos apresentadas na Figura 1 servem como maneira de os usuários em potencial visualizarem os textos que produzem ou que venham a ter que produzir em seu meio social como um todo organizado textual e semioticamente, e podem propiciar, para o ensino-aprendizagem de línguas, um elemento facilitador na aprendizagem.

Uma vez que o uso de EGPs é ainda bastante tímido no ensinoaprendizagem de línguas no Brasil, apresento a seguir alguns aspectos que podem ser explorados e adaptados de acordo com as necessidades de cada contexto.

Com base no uso das EPGs, os aprendizes podem ter contato, do ponto de vista estrutural, com elementos textuais específicos pertencentes a determinados gêneros para a sua integração social, embora esses elementos já existam como conceitos abstratos que circulam no meio social e que são utilizados pelos usuários competentes naquele gênero. O gênero, a partir dessa perspectiva sociossemiótica, passa a ser um elemento de integração social. Isso significa que os conceitos de gênero e de registro, os demais elementos a eles inerentes (estágios, campo, relações, modo), bem como as EPGs aqui apresentadas, sugerem uma visão social de linguagem.

Embora tenham sido apresentadas as EPGs de textos de vídeos institucionais, quaisquer tipos de textos circulando em determinado meio social e pertencentes a determinado gênero que se pretenda utilizar para o ensino-aprendizagem deste gênero específico podem ter a sua EPG estabelecida e, a partir dela, as informações podem circular e ser disponibilizadas para os produtores de outros textos pertencentes ao mesmo gênero.

A adoção dessa prática pode facilitar o reconhecimento e a produção de tais estruturas. Estamos tratando, assim, da operacionalização de conceitos, ou seja, da transformação de algo abstrato, teórico ou conceitual e distante do cotidiano, em algo prático, concreto, que possa favorecer o ensino e a aprendizagem dos gêneros e de sua organização e sua forma ou estrutura. 
Ventola (1984, p. 283) aponta a importância das EPGs para o ensino de línguas estrangeiras, como maneira de ensinar o aprendiz a agir como participante de um processo social com interações em situações de comunicação real. Ou seja, a partir do momento em que o aprendiz tem contato com a estrutura textual utilizada pelos nativos do idioma em diversas situações de interação, pode instrumentalizar-se de maneira a interagir socialmente quando aquela situação ocorrer efetivamente.

Se pensarmos em situações de ensino instrumental de produção escrita, por exemplo, essas estruturas vão funcionar como modelos de referência: quando for necessária a produção de um texto pertencente a determinado gênero, não é necessário que se recrie o gênero, pois este já existe e é utilizado no meio social.

Em trabalho anterior (VIAN JR, 2002), são apontadas experiências com o uso das EPGs para o ensino da produção oral em contextos profissionais. São sugeridos, também (VIAN JR, 2003), os passos para a operacionalização do trabalho com gêneros discursivos para o ensino do oral, especificamente no planejamento e execução de um curso, para alunos executivos, de inglês para reuniões.

A proposta contida em Vian Jr (2003) é similar àquela sugerida por Ramos (2004) para o ensino com base em gêneros a partir de tarefas. A diferença entre as duas é que Ramos baseia-se no trabalho de Swales (1990) e Bhatia (1993), ao passo que a sugestão de Vian Jr parte de uma perspectiva sistêmico-funcional, ou seja, pontos de partida diferentes que, supostamente, levam ao mesmo ponto de chegada, além de outras diferenças que não cabe discutir aqui.

As EPGs também podem ser utilizadas no ensino de língua materna, uma vez que os professores podem, a partir dos gêneros que circulam no contexto educacional e/ou profissional, utilizar textos que sejam relevantes para os alunos em suas futuras interações, em que determinados textos são exigidos como parte das tarefas realizadas e para as quais aqueles utilizados em sala servem de base. Em texto anterior (VIAN JR, 2006) é apresentada uma experiência em que são trabalhados os gêneros utilizados por alunos em um curso de graduação em Ciências Contábeis e os gêneros (resumos, artigo acadêmico e respostas dissertativas de provas) por eles utilizados no meio acadêmico. 


\section{CONSIDERAÇÕES FINAIS}

A análise dos quatro vídeos institucionais desenvolvida neste artigo mostra-nos a estruturação dos textos em estágios, classificados em obrigatórios - comuns a todos os textos componentes do gênero -, opcionais - que só aparecem em alguns dos textos - e recursivos, estágios que se repetem em um mesmo texto.

Ao contrário do que clamam alguns pesquisadores a respeito de outros gêneros - por exemplo, os encontros de serviço analisados por Hasan (1989) e as introduções de artigos científicos analisados por Swales (1990) -, os estágios obrigatórios dos textos aqui analisados têm ocorrência obrigatória, mas sequência não obrigatória, o que não descaracteriza o gênero. Ou seja, o gênero não deve ser visto como uma fórmula a ser prescrita, mas como uma probabilidade a ser verificada em determinado meio social: uma vez que o usuário mostre-se competente na utilização de determinado gênero, passa também a poder adaptar os textos pertencentes àquele gênero a determinado contexto situacional, quando será verificada a necessidade ou não da sequência obrigatória requerida para aquele evento.

Uma vez que os significados não podem ser transmitidos simultaneamente, a necessidade de se estruturar o texto em estágios se faz evidente; o conceito de estágio utilizado neste artigo, portanto, refere-se à denominação dada aos blocos funcionais pelos quais os significados são transmitidos, e, uma vez que os textos se materializem por elementos linguísticos, a escolha desses elementos é determinada por fatores do contexto social e do contexto cultural nos quais os textos são produzidos.

A utilização desses conceitos no ensino de línguas - materna e estrangeiras - pode despertar não só a conscientização dos alunos no processo de produção textual e a importância do contexto na elaboração do texto, mas também a possibilidade de se vislumbrar que as escolhas lexicogramaticais realizadas nos textos são influenciadas pelas variáveis de contexto, das condições de produção e das relações sociais entre produtores e receptores dos textos. 
O uso das estruturas funciona como uma referência no momento da produção textual e fornece um modelo para que os produtores de textos em potencial familiarizem-se com os gêneros a serem utilizados em sua vida cotidiana, tanto acadêmica quanto profissional e pessoal.

A análise aqui apresentada e as experiências dela derivadas revelam a importância da pesquisa sobre a estrutura textual e os gêneros discursivos para posterior utilização em contextos de ensino e aprendizagem não só de línguas estrangeiras, mas também de língua materna, bem como sobre a relação dos padrões existentes entre a linguagem e o contexto, essencial para os estudos nessas áreas.

\section{REFERÊNCIAS}

BAKHTIN, M. Os gêneros do discurso. In: Estética da criação verbal. São Paulo: Martins Fontes, 1992.

BHATIA, V.K. Analysing genre: language use in professional settings. New York: Longman, 1993.

EGGINS, S. An introduction to systemic functional linguistics. London: Pinter Publishers, 1994.

; MARTIN, J. R. Genres and registers of discourse. In: DIJK, Teun van (Ed.). Discourse as structure and process - discourse studies: a multidisciplinary introduction. V. 1. London, Thousand Oaks, New Delhi: Sage Publications, 1997.

GRACIOSO, F. Propaganda institucional: nova arma estratégica da empresa. São Paulo: Atlas, 1995.

HALLIDAY, M.A.K. Part A. In: ; HASAN, R. Language, context, and text: aspects of language in a social-semiotic perspective. Oxford: Oxford University Press, 1989.

; HASAN, R. Language, context, and text: aspects of language in a social-semiotic perspective. Oxford: Oxford University Press, 1989.

HASAN, R. Part B. In: In: HALLIDAY, M.A.K.; HASAN, R. Language, context, and text: aspects of language in a social-semiotic perspective. Oxford: Oxford University Press, 1989. 
MARTIN, J.R. Context: register, genre and ideology. English text: systems and structure. Philadelphia/Amsterdam: John Benjamins Publishing Company, 1992.

; ROSE, D. Working with discourse: meaning beyond the clause. London: Continuum, 2003.

; ROSE, D. Genre relations: mapping culture. London: Equinox, 2008.

PINHO, J.B. Propaganda institucional: usos e funções da propaganda em relações públicas. São Paulo: Summus Editorial, 1990.

RAMOS, R.C.G. Gêneros textuais: uma proposta de aplicação em cursos de inglês para fins específicos. The ESPecialist, v. 25, n. 2, p. 107-129, 2004.

SANTOS, V.B.M.P. Padrões interpessoais no gênero de cartas de negociação. Dissertação (Mestrado em Linguística Aplicada) - Programa de Estudos Pós-Graduados em Linguística Aplicada e Estudos da Linguagem, Pontitífica Universidade Católica de São Paulo, 1996.

SWALES, J.M. Genre analysis: English in academic and research settings. Cambidge: Cambridge University Press, 1990.

TORQUATO, G. Comunicação empresarial, comunicação institucional: conceitos, estratégias, sistemas, estruturas, planejamento e técnicas. São Paulo: Summus Editorial, 1986.

VENTOLA, E. Orientation to social semiotics in foreign language teaching. Applied Linguistics, v. 5, n. 3, p. 275-286, 1984.

VIAN JR., O. Conceito de gênero e análise de textos de vídeos institucionais. Dissertação (Mestrado em Linguística Aplicada) - Programa de Estudos Pós-Graduados em Linguística Aplicada e Estudos da Linguagem, Pontífica Universidade Católica de São Paulo, 1997.

O planejamento de cursos instrumentais de produção oral com base em gêneros do discurso: mapeamento de experiências vividas e interpretações sobre um percurso. Tese (Doutorado em Linguística Aplicada) Pontifícia Universidade Católica de São Paulo, São Paulo, 2002.

- O ensino de inglês instrumental para negócios, a linguística sistêmicofuncional e a teoria de gênero/registro. The ESPecialist, v. 24, n. 1, p. 1-16. 2003.

Gêneros discursivos e conhecimento sobre gêneros no planejamento de um curso de português instrumental para Ciências Contábeis. Linguagem em (Dis)curso, v. 6, n. 3: "Gêneros textuais e ensino-aprendizagem", org. por 
Adair Bonini e Maria Marta Furlanetto, p. 389-4311, 2006. Disponível em: $<$ http://www3.unisul.br/paginas/ensino/pos/linguagem /0603/03.htm>.

Recebido em 29/04/08. Aprovado em 15/07/09.

Title: Text and genre: systemic functional perspectives for genre analysis and language teaching

Author: Orlando Vian Jr.

Abstract: Based on (i) the concept of Genre (HASAN, 1989), its organization in obligatory, optional and recursive stages, (ii) on the concept of Register (HALLIDAY, 1989), its field, tenor and mode variables, and (iii) on the inter-relation between Genre/Register in contextual levels of culture and of situation, corporate image advertising texts are analyzed with the objective of pointing out to the fact that the study of contextual configuration (HASAN, 1989) and the stages which make up a text allows the understanding of textual organizational aspects and of the genres to which texts belong. It is also argued that the contextual configuration elements may be used in foreign language and mother tongue teaching for genre-based teaching-learning programs.

Keywords: genre; text; systemic functional grammar; language teaching.

Titre: Texte et genre: perspectives systémico-fonctionnelles pour l'analyse de genres et pour l'enseignement de langues

Auteur: Orlando Vian Jr.

Résumé: À partir (i) du concept de Genre de Hasan (1989), avec sa composition dans des stages obligatoires, facultatifs et récursifs, (ii) du concept d'Enregistrement de Halliday (1989), avec des variables de champ, relations et moyen, et (iii) de l'interrelation genre/enregistrement dans des niveaux contextuels de culture et situation, on fait ici l'analyse des textes des vidéos institutionnels avec l'objectif de rehausser que l'étude de la configuration contextuelle (HASAN, 1989) et des stages qui composent les textes fournissent des pistes pour la compréhension d'aspects de l'organisation textuelle et des genres auxquels les genres appartiennet. On argumente, encore, que les éléments de la configuration contextuelle peuvent être employés dans l'enseigenement de langues étrangères et de langue maternelle à partir de l'adoption de genres du discours comme objet d'enseignement-apprentissage.

Mots-clés: genre discursif; texte; grammaire systémico-fonctionnelle; enseignement de langues.

Título: Texto y género: perspectivas sistémico-funcionales para el análisis de géneros y para la enseñanza de lenguas

Autor: Orlando Vian Jr.

Resumen: A partir (i) del concepto de Género de Hasan (1989), con su composición en etapas obligatorias, opcionales y recursivas, (ii) del concepto de Registro de Halliday (1989), con sus variables de campo, relaciones y modo, y (iii) de la interrelación 
género/registro a niveles contextuales de cultura y de situación, son aquí analizados textos de vídeos institucionales con el objetivo de evidenciar que el estudio de la configuración contextual (HASAN, 1989) y de las etapas que componen los textos provee pistas para la comprensión de aspectos de la organización textual y de los géneros a los cuales los textos pertenecen. Se argumenta, aún, que los elementos de la configuración contextual pueden ser utilizados en la enseñanza-aprendizaje de lenguas extranjeras y de lengua materna a partir de la adopción de géneros del discurso como objeto de enseñanza-aprendizaje.

Palabras-clave: género discursivo; texto; gramática sistémico-funcional; enseñanza de lenguas.

VIAN JR. - Estruturas potenciais de gêneros... 